\title{
The effect of medroxyprogesterone acetate, administered to the lactating rat, on the subsequent growth, maturation and reproductive function of the litter
}

\author{
N. Satayasthit, M. Tankeyoon and R. R. Chaudhury \\ W.H.O. Research Team, Chulalongkorn Hospital Medical School, Bangkok, Thailand
}

The contraceptive steroid, medroxyprogesterone acetate (MPA), which at a dose of $150 \mathrm{mg}$ can be injected every 3 months, is being considered for more widespread use in family planning programmes of developing countries, e.g. Thailand. Since MPA, in contrast to the combined oestrogen-progestagen steroids, does not decrease but may actually increase milk secretion when administered to lactating women (Karim et al., 1971; Koetswang, Chiemprajert \& Kochananda, 1972) it could be used more for contraception during lactation.

There is no information on the effects of MPA, when administered to the lactating rat, on the subsequent growth, sexual maturation and reproductive function of the young. MPA may be ingested through the milk, as has been demonstrated for the oestrogen-progestagen steroids (Laumas, Malkani \& Laumas, 1971), and affect the release of the gonadotrophic hormones now known to be secreted very early after birth and throughout suckling (Odell, Swerdloff, Abraham, Jacobs \& Walsh, 1971). An investigation was therefore carried out to determine the effect of MPA administered to the lactating rat on growth and other functions of the young.

Adult cyclic female rats of the Charles Foster strain were mated with proven males and the pregnant mother separated in an individual cage throughout pregnancy. At parturition the young in the litter were reduced to five, three females and two males, to ensure that the suckling stimulus would be similar for all the mothers and that there would be adequate milk available for all the young. The following factors were studied in the female young: (i) body weight; (ii) day of vaginal opening; (iii) day of onset of oestrous cycles; (iv) ability to conceive; (v) duration of first pregnancy; (vi) the number of young and their normality; (vii) lactational performance as assessed by weight of the young. The body weight and fertilizing ability of the male young were studied.

The studies were carried out on 28 control and 32 experimental female young and 19 control and 19 experimental male young; the experimental young were produced by 10 rats given $5 \mu \mathrm{g}$ MPA (Depo-Provera: Upjohn Co. Ltd)/g body wt intramuscularly on Day 3 after parturition.

Table 1. The effect of medroxyprogesterone acetate administered to the lactating rat on the subsequent development of sexual characteristics of the female young (means \pm S.E.M.)

\begin{tabular}{lccc}
\hline \multicolumn{1}{c}{ Parameter } & Control young & Experimental young & Significance \\
\hline Age at vaginal opening (days) & $36 \cdot 2 \pm 0 \cdot 3$ & $37.6 \pm 0.5$ & $P<0.05$ \\
Body wt on day of vaginal opening (g) & $123.6 \pm 1.7$ & $130.8 \pm 2.1$ & $P<0.05$ \\
Age at first oestrus (days) & $39 \cdot 3 \pm 0.9$ & $44.3 \pm 1.4$ & $P<0.01$ \\
Duration of pregnancy (days) & $22 \cdot 3 \pm 0.1$ & $22.4 \pm 0.1$ & N.S. \\
No. in litter & $10 \cdot 7 \pm 0.4$ & $10.4 \pm 0.5$ & N.S. \\
\hline
\end{tabular}

The results obtained for the female young are shown in Table 1 . There were no differences in the growth rates of the control and experimental young as observed until Day 60. All the experimental rats became pregnant, and no abnormalities were seen at birth; the sex ratio of the offspring was normal. There did not appear to be any deficiency in the lactational performance in these mothers as the weight curves of their young, male and female, did not differ from those of the young of the control rats.

There was no difference in growth curves up to Day 60 between control and experimental male offspring, and all sired normal healthy young. 
Treatment of lactating females with MPA did, however, significantly delay the onset of vaginal opening and of the first oestrous cycle in the young. This delay was not caused by any difference in the body weight because the growth curves of the control and experimental rats were similar. The significance of this slight delay in sexual maturation, if any, is being investigated.

We are grateful to Dr Puttipongse Varavudhi of the Department of Biology, Chulalongkorn University, for helpful suggestions during the course of the study.

\section{References}

Karim, K., Ammar, R., El Mahgouli, S., El GaNzOURY, B., FIKRI, F. \& ABDou, I. (1971) Injected progestogen and lactation. Br. med. J. 1, 200203.

Koetswang, S., Chiemprajert, T. \& Kochananda, P. (1972) The effects of injectable contraceptives on lactation. Clin. Proc. 1st I.P.P.F. South-East Asia \& Oceania Regional Medical \& Scientific Congr., Sydney, pp. 84-90.
Laumas, V., Malkani, P.K. \& Laumas, K.R. (1970) The possibility of oestrogenic activity in human and goat milk after administration of oral gestogens. Contraception 2, 331-338.

Odell, W.D., SWerdloff, R.S., Abrayam, G.E., JACOBS, H.S. \& WALSH, P.C. (1971) Pituitarygonadal interrelations. In Control of Gonadal Steroid Secretions, pp. 32-64. Eds D. T. Baird \& J. A. Strong. Edinburgh University Press.

Received 27 May 1975 